\title{
The role of MRI in comparison between benign and malignant chest wall masses in correlation with pathology
}

\author{
Marian Fayek Farid Kolta ${ }^{1} \mathbb{D}$, Nessma Kamal Abd El Rheem², Amr Farouk Ibrahim² and \\ Mohammed Raafat Abd El-Mageed ${ }^{1 *}$
}

\begin{abstract}
Background: Tumors that arise from the chest wall (including bone structures such as the sternum, clavicle, scapula, and ribs) or from adjacent soft tissues are less common than other parts of the body, and so the resulting unfamiliarity can make it difficult to limit the number of possible diagnoses. These tumors have a wide range of possibilities, including primary chest wall tumors arising from the bone or soft tissue, which are subdivided into malignant and benign tumors, and the secondary metastatic deposits. The aim of the study is to investigate the ability of MRI with diffusion sequence in differentiation between benign and malignant chest wall masses, which is subsequently reflected in the management of chest wall masses patients.
\end{abstract}

Main body: MRI has superior soft-tissue resolution and value for local assessment of primary tumors and accurate tissue characterization and plays a key role in preoperative staging to assess for multi-spatial and multi-compartment involvement. ADC values were obtained in 31 patients, and the mean ADC values of benign (13 patients) chest wall masses were $1.31 \pm 0.50 \times 10^{-3} \mathrm{~mm}^{2} / \mathrm{s}$ while the mean ADC values of the malignant (18 patients) chest wall masses were $0.98 \pm 0.36 \times 10^{-3} \mathrm{~mm}^{2} / \mathrm{s}$. There was a statistically significant difference between the ADC values obtained from the malignant and benign chest wall masses $(P<0.001)$.

Conclusion: This study demonstrates that diffusion-weighted MR imaging is a growing imaging modality to predict the histopathological differentiation of malignant from benign chest wall masses.

Keywords: Chest wall masses, MRI, Diffusion-weighted imaging, Apparent diffusion coefficient

\section{Background}

Tumors that arise from the chest wall (including bone structures such as the sternum, clavicle, scapula, and ribs) or from adjacent soft tissues are less common than other parts of the body, and so the resulting unfamiliarity can make it difficult to limit the number of possible diagnoses. These tumors have a wide range of possibilities, including primary chest wall tumors arising from bone or soft tissue, which are subdivided into malignant and benign tumors, and the secondary metastatic deposits. The aim of the study is to investigate the ability

\footnotetext{
* Correspondence: mohammed.raafat@kasralainy.edu.eg

${ }^{1}$ Faculty of Medicine, Cairo University, Cairo, Egypt

Full list of author information is available at the end of the article
}

of MRI with diffusion sequence in differentiation between benign and malignant chest wall masses, which is subsequently reflected in the management of chest wall masses patients Figs. 1, 2, 3, 4 and 5.

\section{Main text \\ Background}

Chest wall tumors constitute 5\% of thoracic tumors and less than $1 \%$ of all primary tumors; between 40 and $60 \%$ are malignant. Tumors may originate primarily in the chest wall, may metastasize to it, or extend to it via local invasion from adjacent structures [1].

Benign chest wall tumors are less common than malignant lesions and arise from nerve, blood vessel, osseous, 

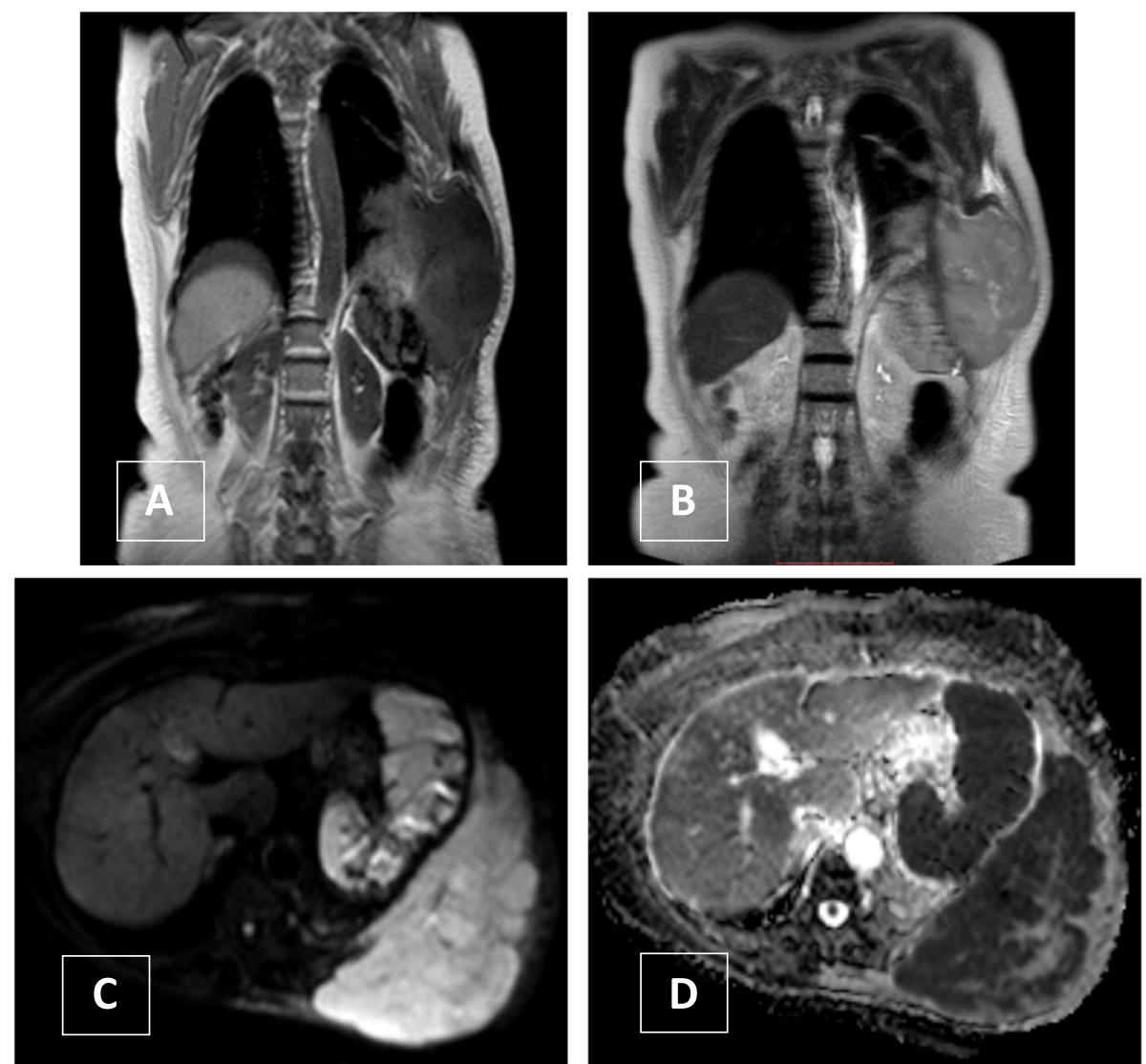

Fig. 1 A 64-year-old female patient presented with progressive pain and swelling at the left lower chest wall. MRI chest wall shows an ill-defined soft tissue mass lesion at the lower left lateral chest wall infiltrating the chest wall, eliciting low signal intensity in T1WI (a), intermediate to low signal intensity in T2 WI (b), and restricted diffusion in the form of high signal in diffusion (c) and low signal in ADC map (d). The ADC value was $0.5 \pm 0.02 \times 10^{-3} \mathrm{~mm}^{2} / \mathrm{s}$, and the mass was pathologically proven to be a large B cell non-Hodgkin lymphoma

cartilaginous, or fatty tissue origin. They include, for example, skeletal benign masses like osteochondroma and fibrous dysplasia, soft tissue masses like hemangioma and elastofibroma dorsi, and neurogenic tumors like neurofibroma [1].

The malignant chest wall masses can be divided into primary or metastatic with further subdivision according to the cell of origin. For example, but not limited to, osseous lesions like metastasis, chondrosarcoma, and plasmacytoma and soft tissue lesions like liposarcoma, angiosarcoma, and neurofibrosarcoma [1].

The degree of restriction to water diffusion in biologic tissue is inversely correlated to the tissue cellularity [2]. In solid malignant lesions, the extravascular extracellular space is relatively diminished compared with the intracellular space due to an increased number of cells, large cell volume, and neovascularization. Therefore, this microstructural density will restrict random water molecule movement [3]. In contrast, a less-cellular environment provides a larger extravascular extracellular space for diffusion of water molecules facilitating random water molecule movement [3].

\section{Methods}

This prospective observation study was conducted on 31 patients (15 males and 16 females) with chest wall masses with their age ranging from 3 to 72 years.

Cases were referred to the radiology department for MRI study assessment after obtaining required consents and were approved by the ethical committee in our department.

The complaints varied between chest wall disfigurement, chest pain, and chest wall swelling.

\section{Inclusion criteria}

Patients with chest wall masses identified on CT.

\section{Exclusion criteria}

Patients with contraindication to MRI including pacemaker, cochlear implants, cerebral aneurysm clips, ocular metallic foreign body, and bullets or shrapnel near great vessels or vital organs.

All cases were subjected to the following: 

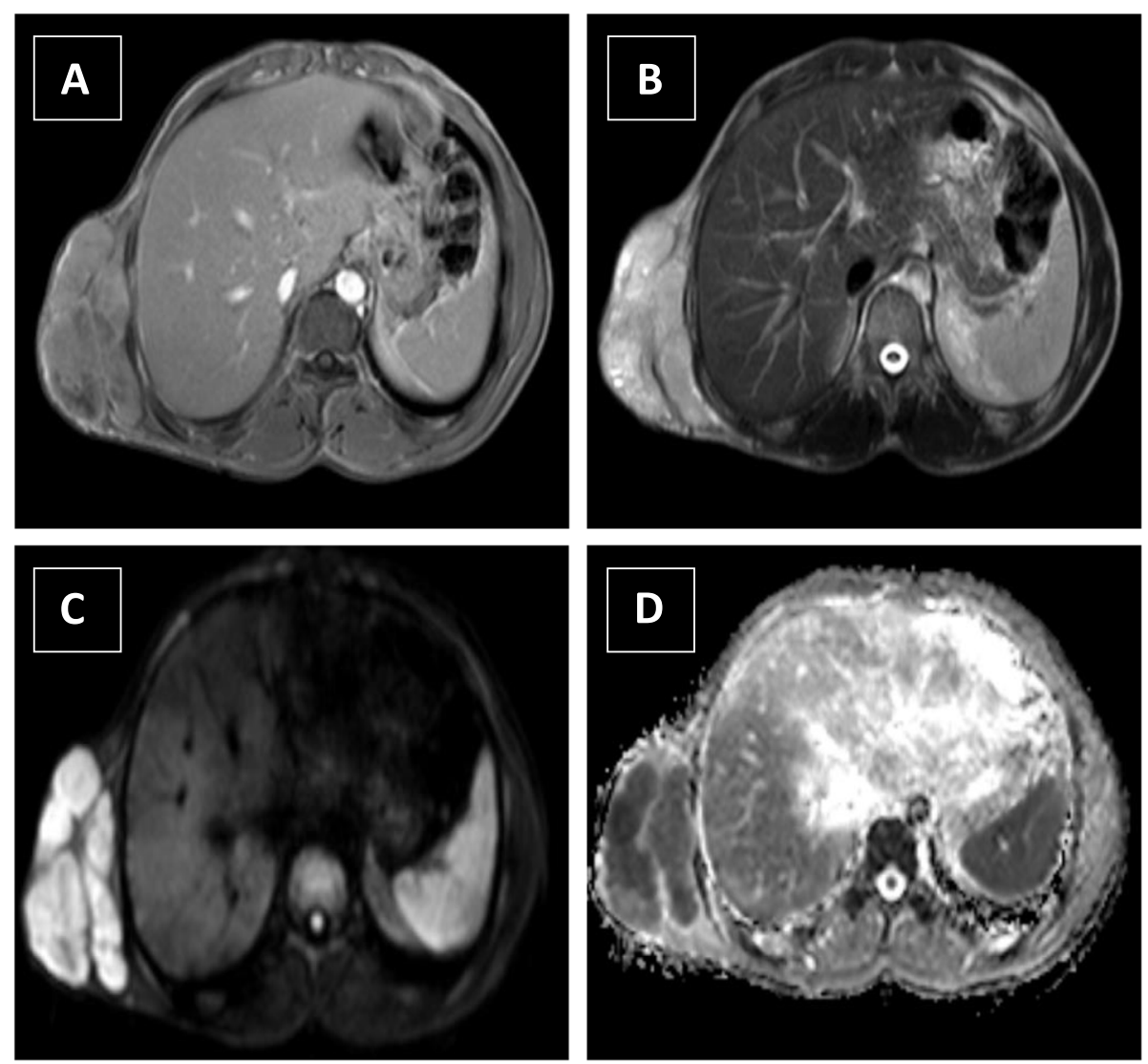

Fig. 2 A 20-year-old male patient presented with right axillary progressive swelling. MRI chest wall shows an ill-defined soft tissue mass lesion at the lower right lateral chest wall with no chest wall infiltration, eliciting isointense signal intensity in T1WI (a), high signal intensity in T2 WI (b), and restricted diffusion in the form of high signal in diffusion (c) and low signal in ADC map (d). The ADC value was $0.4 \pm 0.03 \times 10^{-3} \mathrm{~mm}^{2} / \mathrm{s}$, and the mass was pathologically proven to be a primitive neuro-ectodermal tumor

- Written consent and explanation of the technique and its aim

- Clinical examination

- Obtaining history of their relevant labs and imaging studies

\section{Protocol for MRI study}

MRI of the chest with diffusion was done for all patients with a 1.5-T unit (Achieva; Philips Medical System, Best, The Netherlands).

A 16-channel-phased array torso coil was used to acquire multiplanar sequences with respiratory triggering used. MR imaging was performed in axial T1 weighted image (WI) turbo spin-echo (TSE) $(10 \mathrm{~ms} / 4.6 \mathrm{~ms}$; section thickness: $9 \mathrm{~mm}$; gap: $2 \mathrm{~mm}$; field of view: $420 \times$ $325 \times 306 \mathrm{~mm}$; matrix: $212 \times 179)$, coronal T1 WI TSE $(10 \mathrm{~ms} / 4.6 \mathrm{~ms}$; section thickness: $9 \mathrm{~mm}$; gap: $1.5 \mathrm{~mm}$; field of view: $425 \times 425 \times 208 \mathrm{~mm}$; matrix: $284 \times 246$ ), axial T2 WI TSE (738 ms/100 ms; section thickness: 9 $\mathrm{mm}$; gap: $2 \mathrm{~mm}$; field of view: $420 \times 325 \times 306 \mathrm{~mm}$; matrix: $248 \times 167)$, coronal T2 WI $(738 \mathrm{~ms} / 100 \mathrm{~ms}$; section thickness: $9 \mathrm{~mm}$; gap: $2 \mathrm{~mm}$; field of view: $420 \times$
$325 \times 306$ mm; matrix: $284 \times 246)$; sagittal T2 WI (738 ms/100 ms; section thickness: $8.5 \mathrm{~mm}$; gap: $1 \mathrm{~mm}$; field of view: $400 \times 299 \times 284 \mathrm{~mm}$; matrix: $268 \times 195)$, short T1 inversion recovery (STIR) WI (1788.3 ms/100 ms; section thickness: $10 \mathrm{~mm}$; gap: $2 \mathrm{~mm}$; field of view: 450 $\times 333 \times 334 \mathrm{~mm}$; matrix: $216 \times 161)$, and diffusion weight images (using $3 b$ values: low $\left(0-50 \mathrm{~s} / \mathrm{mm}^{2}\right)$, intermediate $\left(500 \mathrm{~s} / \mathrm{mm}^{2}\right)$, and high $\left(1000 \mathrm{~s} / \mathrm{mm}^{2}\right) b$ values; $1407 \mathrm{~ms} / 66.5 \mathrm{~ms}$; section thickness: $9 \mathrm{~mm}$; interslice gap: $2 \mathrm{~mm}$; field of view: $420 \times 324 \times 306 \mathrm{~mm}$ : matrix $140 \times 107)$.

The apparent diffusion coefficient (ADC) maps were calculated by the MR system via linear regression analysis of the natural log of signal intensity using all three $b$ values $\left(0,500,1000 \mathrm{~s} / \mathrm{mm}^{2}\right)$.

\section{Image evaluation}

MR images were qualitatively analyzed by means of visual assessment of the different pulse sequences and quantitatively assessed by measuring ADC values of the depicted chest wall lesions. 

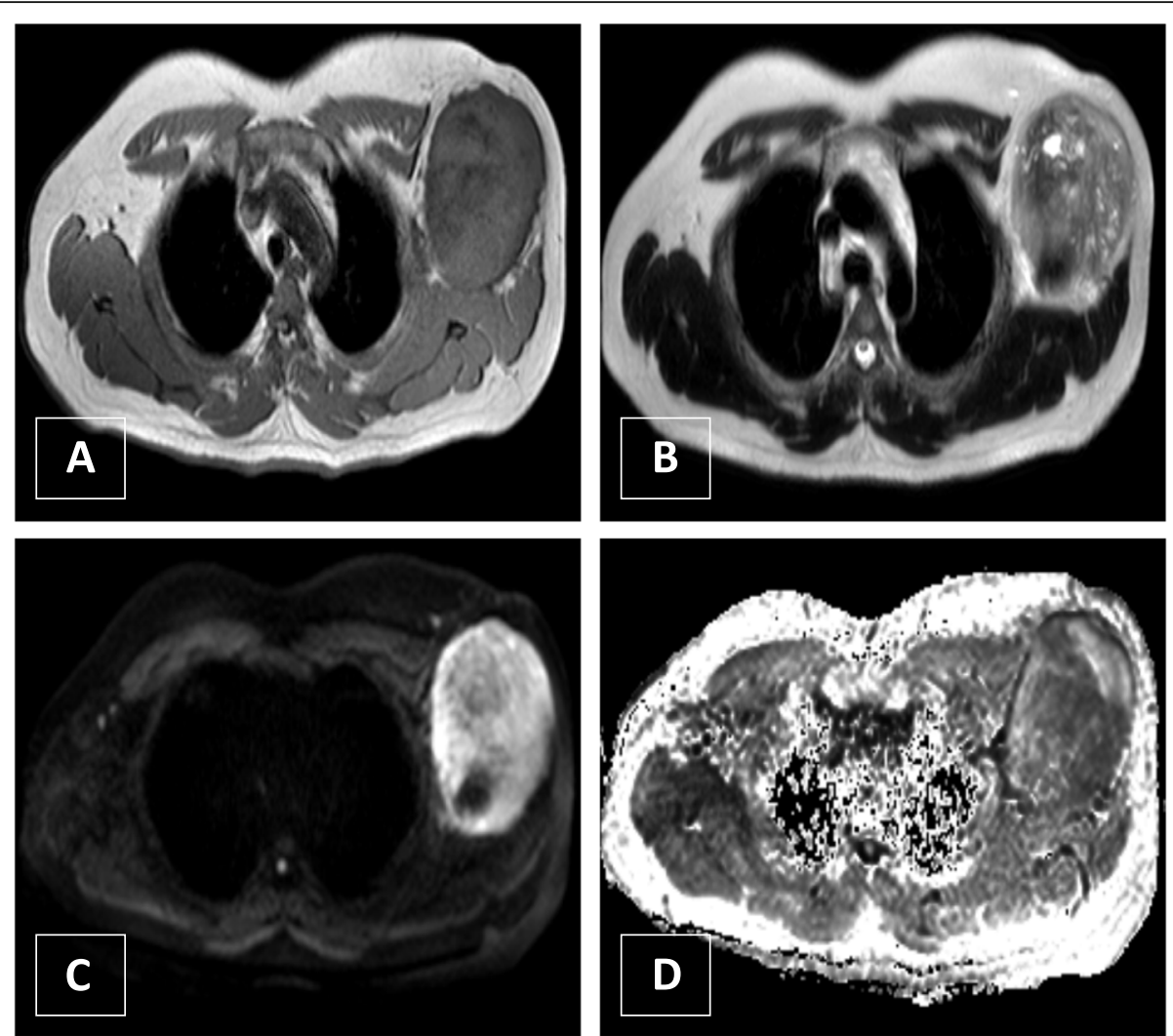

Fig. 3 A 29-year-old male patient presented with left lateral chest wall mass. MRI chest wall shows well-defined soft tissue mass compression the left lateral chest wall with no infiltration of the surrounding structures. The mass exhibits hypointense signal intensity in T1WI (a), heterogeneous signal intensity in T2 WI (b), and restricted diffusion in the form of high signal in diffusion (c) and low signal in ADC map (d). The ADC value was $0.9 \pm 0.04 \times 10^{-3} \mathrm{~mm}^{2} / \mathrm{s}$, and the mass was pathologically proven to be a malignant peripheral nerve sheath tumor (spindle cell sarcoma)
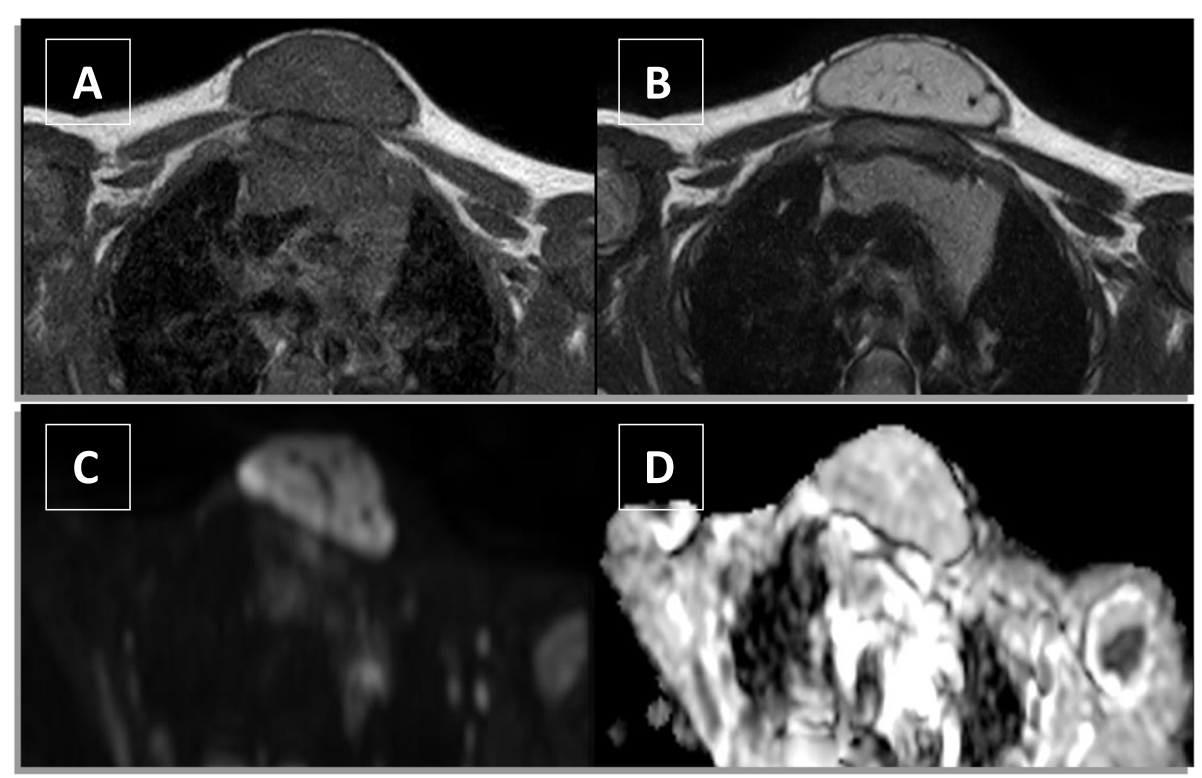

Fig. 4 A 10-year-old male patient presented with anterior midline pre-sternal chest wall mass. MRI chest wall shows a well-defined oval shaped soft tissue mass with related dilated vascular channels and no intra-thoracic extension, eliciting hypointense signal intensity in T1WI (a) and high signal intensity in T2 WI (b) with facilitated diffusion pattern in diffusion WI (c) and ADC map (d). The ADC value was $2.08 \pm 0.05 \times 10^{-3} \mathrm{~mm} / \mathrm{s}$, and the mass was pathologically proven to be hemangioma 

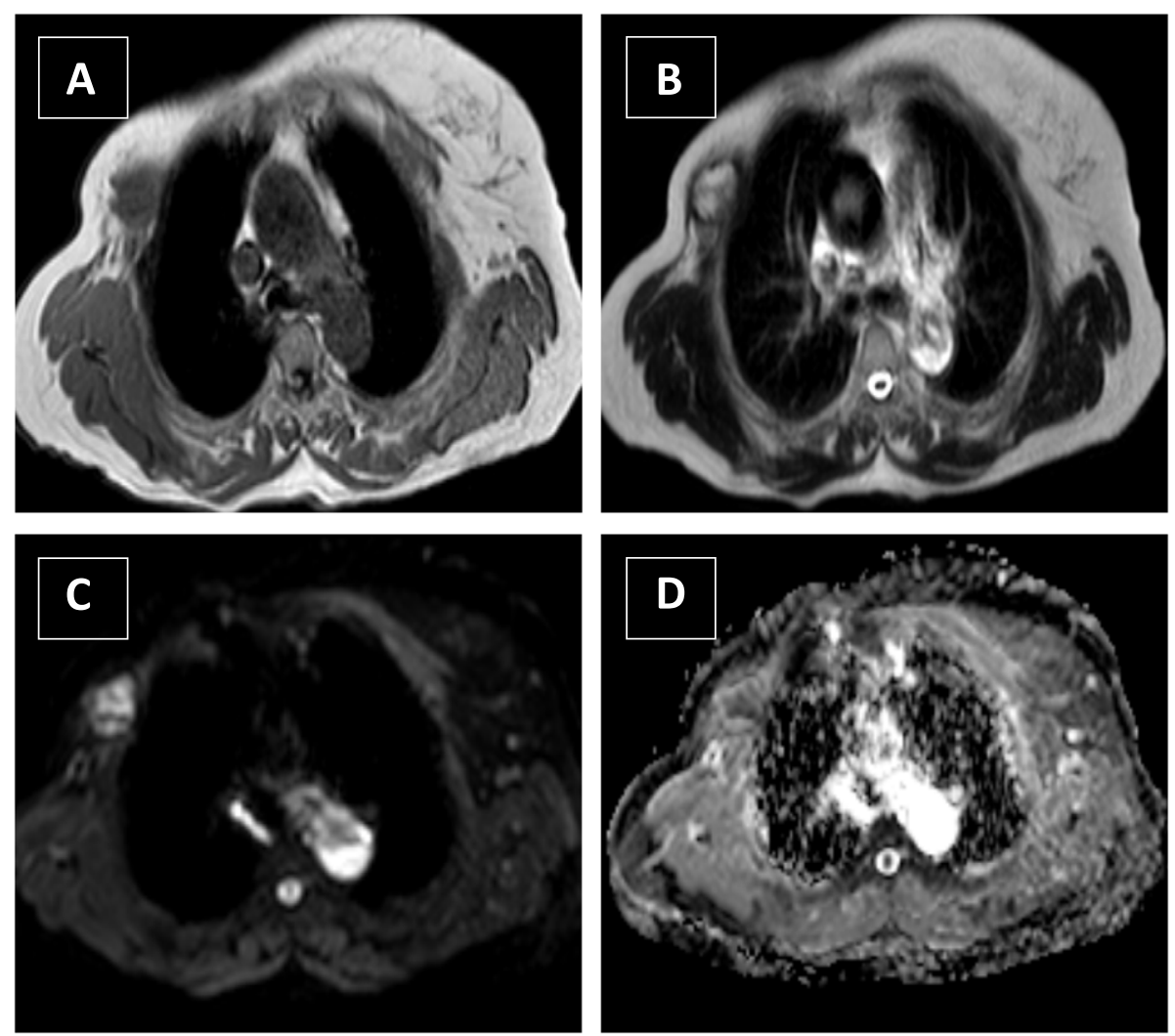

Fig. 5 A 72-year-old female patient presented with postoperative right mastectomy bed swelling. MRI chest wall shows a rather well-defined soft tissue mass at the operative bed with no intra-thoracic extension, eliciting isointense signal intensity in T1WI (a) and intermediate to high signal intensity in T2 WI (b) with intermediate to high signal in diffusion WI (c) and intermediate to low signal in ADC map (d). The ADC value was 1.3 $\pm 0.03 \times 10^{-3} \mathrm{~mm}^{2} / \mathrm{s}$, and the mass was pathologically proven to be a non-neoplastic lesion (cicatricial fibrosis)

Qualitative assessment Chest wall lesions were reviewed for morphological changes (shape and margins) and extent as well as infiltration of the chest wall and lymph nodes association. The signal intensity of each lesion was evaluated on the T1, T2, and STIR WI relative to that of the muscles in the same pulse sequences. Lesions were qualitatively assessed on diffusion-weighted image (DWI) and ADC maps by reviewing their signal intensity on the high $b$ value $\left(b=1000 \mathrm{~s} / \mathrm{mm}^{2}\right)$ DWI and comparing it to that on the corresponding ADC map.

Quantitative assessment ADC values were measured by placing a ROI within the lesion on the trace ADC maps. ROIs were positioned within areas visually judged to be the most restricted (excluding obviously cystic/ necrotic areas).

\section{Histopathological diagnosis}

After MR imaging, patients were scheduled for biopsy and histopathological diagnosis. Taking both lesion accessibility and patient's general condition into account, patients underwent US- or CT-guided biopsies.

\section{Statistical analysis}

Data were collected, coded, revised, and entered to the Statistical Package for Social Science (SPSS) version 20. The data were presented as number and percentages for the qualitative data, mean, standard deviations, and ranges for the quantitative data with parametric distribution and median with inter quartile range for the quantitative data with non-parametric distribution. Chi-square test was used in the comparison between two groups with qualitative data, and Fisher exact test was used instead of the chi-square test when the expected count in any cell found was less than 5 . Independent $t$ test was used in the comparison between two groups with quantitative data and parametric distribution, and MannWhitney test was used in the comparison between two groups with quantitative data and non-parametric distribution. $P$ value is considered significant if $\leqslant 0.05$ at confidence interval $95 \%$.

\section{Results}

This study was conducted on 31 patients with chest wall masses with the following results: 
Among these patients, histopathological assessment confirmed benign nature of the lesions in 13 patients, while malignant lesions were detected in 18 others.

There was a statistically significant result $(P$ value less than 0.05) regarding the lesion infiltration to the surrounding structures, intra-thoracic extension, and presence of associated lymphadenopathy between the benign and malignant masses. All the benign lesions showed no signs of local invasiveness or metastatic lymphadenopathy in contrast to the malignant lesions where associated local invasion of the surrounding structures and accompanying metastatic lymph nodes were encountered (Table 1).

A statistically significant result $(P$ value less than 0.001 ) was observed between the benign and malignant lesions regarding the diffusion signal characteristics, where benign lesions showed facilitated diffusion pattern of low signal in diffusion-weighted images and high signal on ADC map, in contrast to the malignant lesions where they restricted diffusion pattern on diffusionweighted images and ADC map (Table 2).

This table shows that there was highly statistically significant difference in ADC regarding pathological results and statistically significant decrease in malignant in comparison to benign with ADC value (Table 3).

We found that an ADC mean value of $1.2 \times 10^{-3}$ $\mathrm{mm}^{2} / \mathrm{s}$ as a cutoff value can differentiate malignant from benign chest wall masses with sensitivity $96 \%$, specificity $72 \%$, positive predictive value $77 \%$, negative predictive value $83 \%$, and accuracy $88 \%$.

\section{Discussion}

DWI was previously encountered for evaluating intracranial lesions, but nowadays, it is increasingly used for evaluation extra-cranial diseases, including chest wall tumors. The utility of DWI in different MRI studies is largely based on its correlation to histopathology and its added information when intravenous contrast cannot be administered [4].

Diffusion-weighted MR imaging has the potential to improve tissue characterization when findings are interpreted in conjunction with findings obtained with other conventional MR imaging sequences [5].

Table 1 Comparison between pathological results as regards MRI findings: infiltration, intra-thoracic, and lymph node

\begin{tabular}{|c|c|c|c|c|c|c|}
\hline & & \multicolumn{2}{|c|}{ Benign } & \multicolumn{2}{|c|}{ Malignant } & \\
\hline & & $\overline{\text { No }}$ & $\%$ & No & $\%$ & \\
\hline \multirow[t]{2}{*}{ Infiltration } & No & 13 & $100.0 \%$ & 9 & $50.0 \%$ & 0.002 \\
\hline & Yes & 0 & $0.0 \%$ & 9 & $50.0 \%$ & \\
\hline \multirow[t]{2}{*}{ Intra-thoracic } & No & 13 & $100.0 \%$ & 9 & $50.0 \%$ & 0.002 \\
\hline & Yes & 0 & $0.0 \%$ & 9 & $50.0 \%$ & \\
\hline Lymph node & No & 13 & $100.0 \%$ & 13 & $72.2 \%$ & 0.038 \\
\hline
\end{tabular}

Table 2 Comparison between the two studied groups according to the duration of different parameters

\begin{tabular}{|c|c|c|c|c|c|c|c|}
\hline & & \multicolumn{4}{|c|}{ Pathological results } & \multirow{3}{*}{\multicolumn{2}{|c|}{$p$ value }} \\
\hline & & \multicolumn{2}{|c|}{ Benign } & \multicolumn{2}{|c|}{ Malignant } & & \\
\hline & & No & $\%$ & No & $\%$ & & \\
\hline \multirow[t]{2}{*}{ Diffusion } & Low & 13 & $100.0 \%$ & 0 & $0.0 \%$ & 31.000 & $<0.001$ \\
\hline & High & 0 & $0.0 \%$ & 18 & $100.0 \%$ & & \\
\hline
\end{tabular}

The ADC value is estimated to be lower in viable tumor tissue with densely packed diffusion-hindering obstacles than in tissue with less densely packed obstacles, such as tumor necrosis and benign tissue. Hence, the ADC values in malignant lesions are lower than those in benign lesions [6].

Low ADC in biological systems is believed to reflect reduced mean-squared displacement of water molecules due to high cell density and proliferation as well as cell swelling in the tissue (restricted diffusion) [7].

This is agreeing with our study, as the mean ADC value of malignant chest wall tumors was low. Moreover, we found that the more malignant tumors as metastasis had lower ADC values than other malignant tumors as Ewing's sarcoma. This coincides with Matoba et al. [8], who found that the ADCs of well-differentiated adenocarcinoma appear to be higher than those of other histologic chest wall types.

DWI differentiates benign from malignant lesions in the breast, liver, and prostate. We are agreeing with these studies as the mean ADC value of malignant chest wall tumors was significantly lower than that of benign masses $(P$ value $<0.001)[4,9,10]$.

In our study, 13 patients with benign masses showed low signal intensity in DWI and corresponding high signal on ADC maps (facilitated diffusion), whereas all other patients with malignant diseases appeared hyperintense on diffusion images and with low signal intensity on ADC maps (restricted diffusion). The mean ADC value of malignant tumors was $0.98 \times 10^{-3} \mathrm{~mm}^{2} / \mathrm{s}$, and the mean value of benign masses was $1.3 \times 10^{-3} \mathrm{~mm}^{2} / \mathrm{s}$; thus, the difference was statistically significant $(P<0.001)$. These results are in line with the study carried out by El-Badrawy et al. [11].

Table 3 Comparison between pathological results as regards MRI findings: ADC and ADC value

\begin{tabular}{|c|c|c|c|c|c|c|}
\hline & & \multicolumn{4}{|c|}{ Pathological results } & \multirow[t]{3}{*}{$p$ value } \\
\hline & & \multicolumn{2}{|c|}{ Benign } & \multicolumn{2}{|c|}{ Malignant } & \\
\hline & & No & $\%$ & No & $\%$ & \\
\hline \multirow[t]{2}{*}{$\overline{A D C}$} & Facilitation & 13 & $100.0 \%$ & 0 & $0.0 \%$ & $<0.001$ \\
\hline & Restriction & 0 & $0.0 \%$ & 18 & $100.0 \%$ & \\
\hline ADC value & Mean \pm SD & \multicolumn{2}{|c|}{$1.31 \pm 0.50$} & \multicolumn{2}{|c|}{$0.98 \pm 0.36$} & \\
\hline
\end{tabular}


There was significant difference in ADC value between benign and malignant tumors $(P<0.01)$ as shown in a study performed by $\mathrm{Li}$ et al. [12]. This result appears matching with our study result which shows significant difference between benign and malignant chest wall masses $(P<0.001)$.

We found that using an ADC mean value of $1.2 \times$ $10^{-3} \mathrm{~mm}^{2} / \mathrm{s}$ as a cutoff value can differentiate malignant from benign chest wall masses with sensitivity $96 \%$, specificity $72 \%$, positive predictive value $77 \%$, negative predictive value $83 \%$, and accuracy $88 \%$.

In addition to the ADC value of the lesions, we found that there are some other characteristics of the lesions that may affect the results such as the following.

Intra-thoracic infiltration, there was a statistically significant difference in intra-thoracic infiltration between benign and malignant lesions $(P<0.002)$.

Associated lymph nodes, also there was statistically significant difference in lymph node association between benign and malignant lesions $(P<0.038)$.

Being non-invasive, no requirement of contrast injection and absence of exposure to ionizing radiation are examples of the advantages of diffusion WI.

In our study, we found that the differences in ADC values might reflect differences in histopathologic results. Primary or metastatic chest wall diseases had high tumor cellularity leading to lower ADC values compared to the benign lesions. Therefore, DWI can be used as an imaging tool to differentiate metastasis and primary malignancies from benign lesions.

But as many studies, this study encompasses some limitations. First of them is the susceptibility artifacts despite the usage of phase array coil with cardiac gating and respiratory compensation techniques to improve image quality and speed. However, these artifacts were not severe enough to interfere with the diagnostic information gained by different MR sequences.

The second limitation is claustrophobia found with some patients, which require anesthesia to perform the examination. This comes in addition to relative lengthy MRI examination time, which may make some patients discomfort and not very well cooperative.

\section{Conclusion}

Diffusion-weighted MR imaging is a valuable imaging tool to predict differences between malignant and benign chest wall lesions, and further studies would be recommended to add more information to this growing field and in improving image quality.

\section{Abbreviations}

MRI: Magnetic resonant imaging; ADC: Apparent diffusion coefficient; CT: Computed tomography; WI: Weighted image; TSE: Turbo spin-echo; STIR: Short T1 inversion recovery; DWI: Diffusion-weighted image; ROI: Region of interest; US: Ultrasound; SPSS: Statistical Package for the Social Science; SD: Standard deviation

\section{Acknowledgements}

The authors would like to thank all the personnel who contributed in this study.

\section{Authors' contributions}

MF shared in the study conception and design, collecting the patients' data, processing MRI findings at the MRI work station, and in writing and correcting the manuscript and its revision. NK shared in the study conception and design, acquisition of the data, and analysis and interpretation of the data. AF shared in the study conception and design, analysis and interpretation of the data, and drafting of the manuscript. MR shared in study conception and design, acquisition of the data, analysis and interpretation of the data, and drafting of the manuscript. The authors read and approved the final manuscript.

Funding

This study had no funding from any resource.

Availability of data and materials

The datasets used and/or analyzed during the study are available upon reasonable request.

\section{Declarations}

Ethics approval and consent to participate

No individual data was included in the study. This study was approved by the Research Ethics Committee of the Faculty of Medicine at Cairo University Kasr El-Aini in Egypt in October 2019; reference number 1-141019. All patients included in this study gave verbal informed consent to participate in this research. If the patient was unconscious at the time of the study, written informed consent for their participation was given by their legal guardian.

\section{Consent for publication}

All patients included in this study gave written informed consent to publish the data contained within this study. If the patient was unconscious when consent for publication was requested, written informed consent for the publication was given by their legal guardian.

\section{Competing interests}

The authors declare that they have no competing interests.

\section{Author details}

${ }^{1}$ Faculty of Medicine, Cairo University, Cairo, Egypt. ${ }^{2}$ National Cancer Institute- Cairo University, Cairo, Egypt.

Received: 2 December 2020 Accepted: 22 February 2021

Published online: 11 March 2021

\section{References}

1. Refaely Y, (Ceviren: Bostanci K) (2011) Gögüs Duvari ve Sternum Tümörlerigenel Bakis. In: Eriskin Gögüs Cerrahisi (Adult Chest Surgery). Nobel Tip Kitapevileri, Istanbul

2. Lee TJ, Collins J (2008) MR imaging evaluation of disorders of the chest wall. Magn Reson Imaging Clin N Am 16(2):355-379 x. Crossref, Medline, Google Scholar

3. Razek AAKA (2012) Diffusion magnetic resonance imaging of chest tumors. Cancer Imaging 12(3):452-463

4. Samreen N, Lee C, Bhatt A, Carter J, Hieken T, Adler K et al (2019) A clinical approach to diffusion-weighted magnetic resonance imaging in evaluating chest wall invasion of breast tumors. J Clin Imaging Sci 9:11

5. Qayyum A (2009) Diffusion-weighted imaging in the abdomen and pelvis: concepts and applications. Radiographics 29(2009):1797-1810

6. Tan SLL, Rahmat K, Rozalli Fl, Mohd-Shah MN, Aziz YFA, Yip CH et al (2014) Differentiation between benign and malignant breast lesions using quantitative diffusion-weighted sequence on 3 T MRI. Clin Radiol 69(1):6371. https://doi.org/10.1016/j.crad.2013.08.007 
7. Pickles MD, Gibbs P, Sreenivas M, Turnbull LW (2006) Diffusion weighted imaging of normal and malignant prostate tissue at 3.0 T. J. Magn Reson Imaging 23:130-134

8. Matoba M, Tonami H, Kondou T, Yokota H, Higashi K, Toga H, Sakuma T (2007) Lung carcinoma: diffusion weighted MR imaging-preliminary evaluation with apparent diffusion coefficient. Radiology 243:570-577

9. Saito K, Tajima Y, Harada TL (2016) Diffusion-weighted imaging of the liver: current applications. World J Radiol 8(11):857. https://doi.org/10.4329/wjr.v8. i1 1.857

10. Ueno YR, Tamada T, Takahashi S, Tanaka U, Sofue K, Kanda T et al (2018) Computed diffusion-weighted imaging in prostate cancer: basics, advantages, cautions, and future prospects. Korean J Radiol 19(5):832. https://doi.org/10.3348/kj.2018.19.5.832

11. El-Badrawy A, Elzaafarany M, Youssef TF, El-Badrawy MK (2011) Role of diffusion-weighted MR imaging in chest wall masses. Egypt J Radiol Nucl Med 42(2):147-151. https://doi.org/10.1016/j.ejrnm.2011.06.003

12. Li S, Xue H, Li J, Sun F, Jiang B, Liu D et al (2008) Application of whole body diffusion-weighted MR imaging for diagnosis and staging of malignant lymphoma. Chin Med Sci J 23(3):138-144. https://doi.org/10.1016/S1001-92 94(09)60028-6

\section{Publisher's Note}

Springer Nature remains neutral with regard to jurisdictional claims in published maps and institutional affiliations.

\section{Submit your manuscript to a SpringerOpen ${ }^{\circ}$ journal and benefit from:}

- Convenient online submission

- Rigorous peer review

- Open access: articles freely available online

- High visibility within the field

- Retaining the copyright to your article

Submit your next manuscript at $\boldsymbol{\nabla}$ springeropen.com 